\title{
Preparing a Financial Incentive Program to Improve Adherence to ART for Scale: Using an Implementation Science Framework to Evaluate an mHealth System in Tanzania
}

\section{Laura Packel ( $\sim$ lpackel@berkeley.edu )}

University of California Berkeley School of Public Health https://orcid.org/0000-0002-8186-5246

\section{Carolyn Fahey}

University of California Berkeley School of Public Health

\section{Atuganile Kalinjila}

Health for a Prosperous Nation

Agatha Mnyippembe

Health for a Prosperous Nation

Prosper Njau

National Aids Control Programme

Sandra I McCoy

University of California Berkeley School of Public Health

\section{Research}

Keywords: HIV/ADS, ART, Conditional Cash Transfers, Adherence, Viral Suppression, Implementation Science

Posted Date: June 7th, 2021

DOl: https://doi.org/10.21203/rs.3.rs-548235/v1

License: (c) (i) This work is licensed under a Creative Commons Attribution 4.0 International License. Read Full License 


\section{Abstract}

Background: Viral suppression is key to ending the HIV epidemic, yet only $58 \%$ of people living with HIV (PLHIV) in sub-Saharan Africa are suppressed. Cash transfers are an effective strategy to improve adherence, but little is known about optimization of implementation; for example, designing effective programs that integrate into existing clinic workflows. We studied implementation of an mHealth system to deliver cash transfers to support antiretroviral medication (ART) adherence.

Methods: We conducted an "implementation science-effectiveness" randomized controlled trial evaluating cash transfers conditional on visit attendance for viral suppression among Tanzanian PLHIV initiating ART. An mHealth system using fingerprint identification and mobile payments was used to automatically disburse mobile money to eligible PLHIV. We used Proctor's framework, assessing implementation of the mHealth system from the perspectives of PLHIV and clinicians. We analyzed mHealth system data and conducted surveys $(n=530)$ and in-depth interviews $(n=25)$ with PLHIV, clinic and pharmacy staff $(n=10)$, and structured clinic observations $(n=2,293$ visits).

Results: 1,651 cash transfers were delivered to 346 PLHIV in the cash arms, $78 \%$ through mobile money. Among those in the cash arms, $81 \%$ registered their mobile money account with the mHealth system by study end, signaling high adoption. While acceptability for fingerprinting and mobile payments was high among PLHIV, interviews revealed mixed views: some had privacy concerns while others felt the system was secure and accurate, and provided some legitimacy to the clinical visits. Pharmacists praised system efficiency, but concerns about duplicative recordkeeping and added work arose. Clinic staff voiced excitement for the system's potential to bring the cash program to all patients and simplify workflows; yet concerns about multiple systems, staffing, and intermittent connectivity tempered enthusiasm, highlighting structural issues beyond program scope. Structured observations revealed a steep learning curve; repeat fingerprint scans and manual entry declined as the system improved.

Conclusions: Biometric identification and mobile payments were acceptable to most patients and staff. Fingerprinting encountered some feasibility limitations in the first months of testing, however mobile payments were highly successful. Biometric identification and mobile payments may provide a scalable mechanism to improve patient tracking and efficiently implement financial incentives in low-resource settings.

\section{Trial Registration}

Name of the registry: clinicaltrials.gov

Trial registration number: NCT03351556

Date of registration: $11 / 24 / 2017$

URL of trial registry record: https://clinicaltrials.gov/ct2/show/NCT03351556?

term=mccoy\&cntry=TZ\&draw $=2 \&$ rank $=4$ 
Checklists: StaRI (included with submission). Note CONSORT for cluster randomized trials was used for the main trial but is not directly applicable to this manuscript.

\section{Contributions To The Literature}

- This study uses a robust, implementation-effectiveness hybrid design to optimize the cash transfer implementation strategy for improving retention in care and viral suppression among ART initiates

- Our mixed-methods approach uncovered unanticipated benefits and challenges to implementing cash transfers in a clinical setting - important insights for program directors and policy makers in low-resource settings considering cash transfer programs

- Our results illustrate how an mHealth system can streamline implementation of a cash transfer program, increasing the potential for sustainability and scale.

\section{Background}

For people living with HIV (PLHIV), antiretroviral therapy (ART) is an effective strategy to clinically suppress the virus, providing the dual benefit of improved health and vastly decreased risk of transmission. Despite the robust evidence, this highly effective intervention has not yet reached all that could benefit. For example, in Tanzania, of the 1.6 million people living with HIV, only $62 \%$ are virally suppressed, and of those who are currently on HIV treatment, $87 \%$ are virally suppressed $(1,2)$ - falling short of the "95-95-95 goals" that UNAIDS has set for 2030 for which $95 \%$ of those on HIV treatment should be virally suppressed.(2) To reach these goals, new and effective implementation strategies that can put evidence into widespread practice and bring sustained HIV treatment for viral suppression to all PLHIV are needed. mHealth systems, in combination with other evidence-based implementation strategies, have the potential to facilitate reaching the 95-95-95 goals by streamlining clinic-based recordkeeping, improving care coordination, and simplifying intervention implementation.

Cash incentives are increasingly recognized as one such evidence-based implementation strategy: these programs typically provide cash (or other incentives) to participants who meet a particular condition, for example testing for HIV, thus motivating certain behaviors that result in improved health. There is now a substantial evidence base demonstrating the effectiveness of cash transfer programs in improving outcomes along the HIV care continuum in low resource settings in a research context (2-19). Despite this strong evidence and the increasing prevalence of large-scale government run cash transfer programs for social protection, few cash transfer programs to improve HIV outcomes have been scaled. One possible reason for this gap is that simplified, automated models for implementing these clinic-based programs at scale have yet to be developed and evaluated.

In order to begin to address this gap, we conducted a randomized controlled trial evaluating two cash transfer sizes ( $\sim 5$ and $\sim \$ 10)$ conditional on visit attendance, with the outcome of viral suppression at 6 months among PLHIV recently initiating ART in Shinyanga, Tanzania. Results of the trial indicated that the cash was effective in improving viral suppression at 6 months especially with the larger cash amount. 
(20) For a clinic-based cash transfer program contingent on visit attendance to be scalable and sustainable in resource constrained settings the delivery model must be simple. We developed an mHealth system designed to automate and simplify cash distribution through integration with mobile money providers. The mHealth system had the dual purpose of monitoring compliance (visit attendance) through biometric identification and automatically delivering cash transfers to those who were eligible, obviating the need for manual monitoring of compliance with clinic visits and manual delivery of cash. (21)

In this manuscript we present the results of the implementation science portion of the trial, guided by Proctor's implementation science framework.(22) The overarching goal of the evaluation was to understand from both clinician and patient perspectives the level of fit of the mHealth system with current health systems in Tanzania, and thus to provide recommendations for bringing the system to scale, consistent with Tanzania's country-level strategic goals relating to mHealth.(23)

\section{Methods}

\section{Setting}

This study took place within four HIV care and treatment clinics located in the Shinyanga region of Tanzania. Shinyanga is located in the Lake Zone region of Tanzania, a rural part of the country where over 4.5 million people live in poverty (32-35\% of the population) (24). Adult HIV prevalence in Shinyanga is $5.9 \%$ (4.7\% nationally); among those living with HIV in Shinyanga, approximately $40 \%$ are virally suppressed (52\% nationally).(25)

\section{Intervention}

This paper reports on a mixed-methods, implementation science study nested within a randomized controlled trial, which has been described in detail elsewhere(20). Briefly, from April to December 2018, 530 adult PLHIV who were initiating ART were enrolled and randomized to three arms: standard of care, smaller cash transfer intervention ( $\$ 4.50$ US) and larger cash transfer intervention ( $\sim 10$ US). Participants in the intervention groups were provided with the cash transfer contingent on monthly appointment attendance during the first 6 months of HIV treatment; the primary outcome was viral suppression as measured at the 6-month appointment. Attendance monitoring and cash transfers were implemented using a tablet-based mHealth system (described below). This sub-study focused specifically on the successes and challenges of the intervention implementation strategy.

\section{Description of the mHealth System}

To confront the time-consuming process of patient attendance monitoring and verifying the conditions for cash transfers, and to simplify the logistics of the cash transfer payments, in collaboration with a local (Tanzania-based) technology firm, we created an mHealth system with the following key components: (1) pharmacy-based monitoring of patient visit attendance; (2) biometric identification using fingerprinting; and (3) cash disbursement for those in the intervention group integrated with all 
mobile money providers in Tanzania. Individual mobile money account details were registered in the mHealth system during enrollment for participants who had access and consented to mobile payments. The mHealth system was designed to be implemented in the pharmacies co-located within HIV primary care clinics; upon picking up medication, all participants were to use the fingerprint scanner to register in the system. The system then displayed a form in which the pharmacist or research assistant entered specifics about the medication dispensed (type of ART and number of pills) as well as the next appointment date. For those in the intervention groups, upon completion of the pharmacy visit form, the cash transfer would then be automatically sent to the registered mobile phone number via mobile money (cash was available to those who did not have access to mobile money). Once received (typically within minutes), the participant receives an SMS confirming receipt of the transfer. The key design components of the system, the intended functionality of those components, their intended benefits, and learnings from the implementation study are detailed in Table 1.

Following the launch of the mHealth system in the study clinics, we made iterative improvements to overcome fingerprint recognition challenges related to network outages, data storage and processing limitations, and low image quality due to hardware issues, patient unfamiliarity with fingerprinting, and worn or damaged fingerprint patterns among patients who perform manual work.

\section{Participants}

The implementation science study participants included a subset of PLHIV enrolled in the RCT, as well as clinical staff from the four study clinics. Participants in the cash groups were to share preferences on mobile money and a subset of all participants was asked for more detailed feedback about the entire mHealth system (described below). In-depth interviews were also conducted with 25 PLHIV who were selected using purposeful sampling (equal distributions of men and women in both of the two cash groups). We also recruited 10 clinic and pharmacy staff at the four study clinics; clinic staff were purposively sampled to represent pharmacists, nurses, doctors, and heads of clinics.

\section{Data Collection - Surveys}

At the 6-month follow-up visit, a subset of participants were asked about two aspects of the mHealth system using an adapted version of the Health Information Technology Usability Evaluation Scale (HITUES)(26): the biometric identification feature $(n=104$ participants from all study groups) and the automatic mobile money disbursement ( $n=53$ participants from the intervention groups). The HITUES is divided into four domains to assess the impact, usefulness, ease of use, and user control of the system from the perspective of the patient (see supplemental Table $\mathrm{S} 1$ for all questions, by domain). Possible responses were on a 5-point scale of agreement, with higher scores relating to strong agreement with the presented statement. In addition, all participants in the cash groups $(n=346)$ were asked about their preferences for mobile money versus cash in hand. All surveys were conducted using Qualtrics offline surveys.

\section{Data Collection - In-depth Interviews}


We conducted semi-structured in-depth interviews (IDIs) with PLHIV ( $n=25)$ and clinic and clinical staff $(n=10)$. PLHIV were asked about their experience with the biometric fingerprinting system of the mHealth system and about their experience with the cash transfer (via mobile money or cash). These interviews were conducted at the 6-month follow-up visit. Clinical staff were asked about the mHealth system as a whole and their experience using it as part of clinic operations in the context of the study. Interviews with clinical staff were conducted at the end of the study. All qualitative interviews were conducted in Kiswahili and recorded, transcribed and translated into English.

\section{Data Collection - Structured Observations}

Four months into the study, we initiated structured observations in all of the study clinics ( $n=2,293$ visits) to document functionality of the biometric identification system and the mHealth system. Data were collected on a per visit basis (not containing identifiable information), and documented using Google Forms. Data were then imported into STATA for analysis.

\section{Implementation Outcomes}

We explored outcomes from Proctor's implementation science framework(ref) from both the PLHIV and clinic staff perspectives. Specifically, we triangulated data from multiple sources to evaluate the following outcomes: appropriateness, acceptability, fidelity, adoption, coverage and sustainability. Table 2 lists each outcome, the adapted definition of that measure for this study context, the indicator used to assess the outcome, the data source used, and which population the outcome applies to, e.g., PLHIV or clinical staff. (The subsequent results section is organized by implementation science outcome and participant perspective.)

\section{Analysis}

Descriptive analyses of quantitative data collected through surveys and structured observations were analyzed using STATA statistical software(27). Qualitative data were analyzed using an inductive data analysis approach(28), and themes were documented by two coders as they emerged. Coding was completed by one member of the US team and one member of the Tanzania team; codes were compared and coding discrepancies were discussed and resolved. All coding was conducted using Dedoose(29).

\section{Results}

Table 3 shows the demographic information for the 530 PLHIV enrolled in the full trial, the subset of the 104 PLHIV who responded to the HITUES survey and the subset of 25 PLHIV who participated in the indepth interviews. The mean age ranged between 34 and 36 years, and across the three groups the majority of participants ( 60\%) were women. Most were in a monogamous marriage, and initiated ART at WHO clinical HIV stage 1 . The majority reported having access to a mobile phone at baseline (88\%-100\%), slightly fewer reported having access to mobile money at baseline. By the end of the study, $81 \%$ of participants had registered their mobile money account with the mHealth system.

\section{Acceptability}


We found that most PHIV were comfortable with the fingerprint scanning and the mHealth system overall, especially given the growing ubiquity of biometric identification in Tanzania. Several mentioned that biometrics are the way things are moving in the country, and that many businesses are already using it.

The good thing [about the fingerprinting] is about confirmation, because if the fingerprint is not yours then the system won't confirm.... I think fingerprints are clearer therefore service provision becomes easier... I knew it was something useful in most sectors that's why I didn't see any problem or feel bad.

Some PLHIV felt that fingerprint scanning added not only accuracy in confirming their identity, but also legitimacy, security, and enhanced reliability in tracking visits and medication pick up.

The current system which we used to scan should continue...this system is assured...the data remain safe and in a good system. By the previous system, you can forget, you can also lose the papers; different from the current system where information is kept electronically.

Participants noted that the fingerprint system simplified the appointment process and remarked that they spent less time at the clinic once they started using the fingerprinting and mHealth system. While the mHealth system did not completely obviate the need for paper files, the perception among some was that the system did streamline the clinic process and procedures. However, in contrast to those who talked about the efficiency or simplicity of the system, some participants brought up that they felt the system caused delays at the clinic because of its dependency on a reliable network connection, and delays related to staff who were not proficient with the system.

What I can say is sometimes when you come [to the clinic] and meet one person. When you come another time you find a new person. So, some pharmacists were good and some I can say didn't know how to use it [mHealth system], so if you meet with the one who is well experienced you don't spend a lot of time but another might tell you the system is not working because they don't know how to use it.

\section{Mobile Money: Patient Perspective}

Using the survey and enrollment data, we found high levels of acceptability of the mobile money system and the fingerprint registration process among PLHIV. Nearly all (99\%) of those who had access to a mobile bank account consented to automatic cash disbursement through mobile money. Further, we found that $98 \%$ of eligible participants consented for the study (consenting included fingerprint scanning).

In both IDIs and the structured survey we asked participants (in the cash groups) about their experiences receiving the cash, and regardless of how they received the cash during the study, whether they would in general prefer to receive the transfers in cash or delivered through mobile money. The interviews point to considerable variation of preferences for delivery in cash as compared to delivery as mobile money, and considerable variation in the rationale cited for these preferences. Specifically, one theme that emerged 
related to the acceptability of mobile money included accuracy, safety, and reliability. For example, those preferring the cash transfer delivery via mobile money noted that this method was more secure and more accurate:

I can say there is accuracy because when money is sent from the machine to my phone it means there is a report that will be sent. Therefore, there is no security in giving someone cash in hand because the sender may not get the money to the intended person or they might. So, there are two possibilities but the system is more accurate.

A second theme that was discussed related to control over spending and ability to save money. Interestingly, several PLHIV talked about how they used delivery via mobile money as a way to save or control spending; they were less likely to simply spend the cash on the way home if the money was in their phone versus in their pocket, for example.

... another thing is when you have the money in hand you may end up spending all of it in things that are of no importance., But when it's in the phone you can leave the clinic ... and the money remains in your phone. When you get a problem you withdraw it but if you have it in hand you get tempted to buy random things that aren't important. So keeping it there helps, it's like a small bank, your personal bank.

A third theme that was brought up by PLHIV related to privacy concerns. Some noted that mobile money offered increased privacy compared with receiving cash; in particular, mobile money was discreet enough that their participation in the study could remain private and was not revealed to others attending the clinic, for example. However, others noted that they felt that the cash was more private that the mobile money option - some expressed concern that someone would see the message on the phone that appears when the money has been delivered and know they received money. Related to this, some women noted that cash allowed for more decision-making power - for example they may share a phone with their partner, and if the money is delivered through the phone, their partner will see the SMS message, and they will no longer be able to decide how to spend the money on their own. In addition, others noted that they were concerned that the SMS message alerting them that the mobile money had been delivered might reveal something about their HIV status or that they were participating in a study.

I: Why you like to receive [the cash] at hand?

R: Because I live with my husband there at home and he is not supportive to children, sometime my children may need a small amount of money to use at school but he will not help. Sometime they need books, so it helps me but if sent through the phone, he must know it when he read the messages in my phone and he will start to question and this will be a problem.

Other themes that emerged related to preference for cash over mobile money included concerns about the technology infrastructure (e.g., the unreliable nature of the network) and fees related to the use of mobile money services (see supplemental tables for sample quotes). 
To understand the level of acceptability of the mHealth system among clinical staff, we evaluated themes emerging from the in-depth interviews with clinicians, pharmacists and pharmacy staff. We defined acceptability from the clinical perspective as the degree to which the mHealth components are considered reasonable and satisfactory given current clinical working environment. One of the themes that emerged in discussing the mHealth system with the clinical staff related to the perception that of the system into the clinics would result in additional work for the staff.

...on the side of staff, it [mHealth system] will be something new which has been added to them, it will be a new task which used not to be there, this is what I see will be like a challenge to workers because they will see it as an extra work, it can bring like a sort of resistance to change but with time they will cope it.

A second theme that emerged was related to training on the system - some noted that the system was easy to use once they had adequate training, that it simplified their work, and helped with managing patient flow within the clinic.

... at first, I didn't know how to use this system but now I can use it very well. At first, I was afraid to use this system and I told them that I can't work with it and they told me that you will know it, so they directed me how to use it and I can now use it.

Finally, a theme related to system fatigue emerged in our discussions with the clinical staff. Some clinicians noted that many systems come and go as part of research or government programs, and the clinics often do not see any lasting benefit.

R: Because these systems are always present... and other new systems will keep coming, because there are even some new systems that we did not find here before, but the kept coming and we captured them and we are still working with them till now and they are good, so even if this one comes officially then I hope that it will be captured by the servants and they will just understand.

\section{Appropriateness}

\section{Patient Perspective}

We used the HITUES to assess the appropriateness of the automated mobile money system and the fingerprint components of the mHealth system among PLHIV (Table 4). We adapted the HITUES to explore domains of appropriateness, defined here as the perceived fit of the mHealth components (mobile money, fingerprinting) within the existing clinical care context for PLHIV. Those four domains included impact, usefulness, ease of use, and user control (see supplementary materials for full question text). The overall average score for the scale as it related to using fingerprinting for biometric identification was 4.1 (out of a total possible 5.0). Scores for the fingerprinting showed even less variation than those for the automatic mobile money disbursement, ranging from 4.0 (usefulness domain) to 4.2 (user control domain). 
The overall average score for the scale as it related to the automatic mobile money disbursement (compared to receiving cash in hand) was 4.2 out of a possible 5 , indicating that participants found the system both acceptable and useful, with minimal variation by domain. The impact domain had the highest average score (4.3 out of a possible 5 points).

\section{Clinical Staff Perspective}

We explored appropriateness of the mHealth system with clinical staff through the in-depth interviews. We defined appropriateness as the perceived fit of the mHealth system components within the existing clinic context. Discussions converged around the following themes: technical difficulties, staff shortages and staff turnover, facilitation of patient follow-up, benefits for the patients, and spillover effects for patients not enrolled in the study.

In terms of technical difficulties, some staff expressed frustration, as the system did not always work, and was dependent on having a reliable network connection.

Maybe what gives me a challenge is your system of research, for example a customer may come, you will pass him/her through the system, if the customer put his/her finger prints, the system fails to show recognition, you may try the left hand but it does not respond, the same with the right hand also, so you have to use the ID number, so this is what challenges me.

Other clinicians discussed the difficulties of implementing the systems when there are substantial staff shortages and staff turnover. Such shortages meant that job duties and roles changed regularly, as managers shifted staff around to cover gaps.

My opinions are, first let me start with the positive ones, the admission of the system went hand in hand with offering of benefits to the clients and it even helped us in reducing the number of lost follow-up clients meaning on those days that a client is on appointment, he does not show up, though it had its challenges.

Additionally, others noted that the system helped with reminders for when patients were due for viral load testing, and some pointed out the potential for the system to help with patient follow-up across clinics if the system were to be implemented nationally or even regionally.

My feeling is that [with the system], we will first reduce LTF [loss to follow-up] and there will be frequent tests because if a patient scan his/her details will automatically come as the way they are and I think that a person can test himself or herself in another place, If he/she has already being recruited in this system, I think if he/she just scan, the details will appear automatically, so we will reduce LTF because most of the LTF appeared because of repetition of testing, you may find that he/she was taking medicine from another place and then he/she come to our place and find it difficult to follow his/her transfer or he/she has lost the card so he/she decide to do new registration. I think re-registration of patients will end. 
Several clinicians talked about how the mHealth system benefitted patients during the study, and discussed how the mHealth system had the potential to benefit all patients in the clinic were the system to be implemented broadly. Specifically, they noted that the system helped patients transition from every month prescription pick-ups to 3-month prescription pick-ups as it helped with visit attendance and thus with adherence.

Others recognized that the system helped patients come to appointments on schedule and remarked that the system led to more complete viral load testing as it helped to reduce loss to follow up. Finally, some clinicians recognized that the system had positive spillover effects even for those who were not enrolled in the study.

...because the system is there and there is a close follow up, it helps to remind us that the patient is required to conduct a test, it has motivated us and increase our attention in making follow up, not only for those who are in the system but also for all patients in general, it has helped us improve the service in the HVL [HIV viral load testing] in general.

\section{Adoption}

\section{Patient Perspective}

To measure adoption, we explored the proportion of PLHIV study participants who had their mobile bank accounts linked to the mHealth system at the end of the study. At the end of the study, $88 \%$ of study participants reported that they had access to a mobile phone, $78 \%$ reported that they had access to a mobile money account, and among those in the cash groups, $81 \%$ had registered their mobile money account with the mHealth system.

\section{Clinical Staff Perspective}

We measured adoption from the clinical staff perspective by examining the proportion of time that the pharmacist was operating the mHealth system - the intended design. As the mHealth system was rolled out in the clinics, research assistants provided significant levels of support to the pharmacist in registering patients with the mHealth system, however, by the end of the study, the pharmacist was operating the system on average $72 \%$ of the time (as opposed to the research assistant being the primary operator).

\section{Fidelity}

\section{Patient Perspective}

Among PLHIV in the cash award groups ( $n=346), 331$ (96\%) received at least one cash transfer during the 6-month study, and the average number of cash transfers per study participant was 4.7 (out of a possible 6 transfers). Out of a total of 1,651 cash transfers delivered to study participants, 1,283 (78\%) were 
delivered through mobile money (the remainder were paid to participants in cash) and $2.5 \%$ of those sent through mobile money required manual re-sending due to network failures.

\section{Clinical Staff Perspective}

To assess fidelity of implementation from the clinical staff perspective, we looked at the proportion of visits for which the mHealth system was used. Over 3,067 total clinical visits across all four health facilities during the 6 months following study enrollment, 172 (5.6\%) were not captured in the mHealth system; $94.4 \%$ of all visits were registered into the mHealth system at the time of visit. The proportion of visits for which the mHealth system was used ranged from $94.6 \%$ to $89.1 \%$ by clinical site.

\section{Feasibility - Clinical Staff Perspective}

To assess feasibility, we focused on the technological aspects of the mHealth system implementation, exploring how frequently the fingerprint scanning system and mobile money distribution systems failed. The clinic pharmacy structured observations captured data on 2,293 patient visits over the course of the study. Observations were focused on the use of the mHealth system during clinic visits and included the number of fingerprint scans required until the mHealth system successfully identified the patient, and whether or not the fingerprint scan was eventually successful in identifying the patient (regardless of the number of scans required). It should be noted that as more PLHIV enrolled in the study and more fingerprints were added to the database, finding correct fingerprint matches became more complex, and required several iterations of the matching algorithm. Overall, fingerprint recognition succeeded for $74.1 \%$ of visits while $25.9 \%$ required manual entry of the patient's unique identification number due to poor image quality. The success rate for fingerprint recognition increased over time; by the final month of structured observations, the success rate was $87.3 \%$ (Figure 1). Overall, the average number of fingerprint scans required for the mHealth system to successfully identify the patient was 2.04 ; this also varied considerably by study month, and by the end of the study, the average number of scans was 1.8 .

\section{Sustainability - Clinical Staff Perspective}

In an effort to explore scale-up and sustainability, we asked the clinicians about what challenges they might anticipate encountering should the mHealth system offset some paper-based aspects of the current recordkeeping system. Many of the themes that emerged had already been mentioned, including the importance of training, considerations related to staff turnover, and the need for a salary top-up as many staff saw use of the system as an added task rather than as a way to simplify or facilitate their existing work.

The potential benefit for patients was another theme that arose when discussing sustainability of the mHealth system. Several clinicians noted recognized the potential benefits and mentioned that with adequate training, they would be prepared for the new system.

We are positively ready for it [mHealth system] as I have said that we have observed its high impact within this short time of using it. So, for us we have received it with all our hands and we wish if it would 
come earlier, it would be more better because data shows, data shows us that it has good results so we are well prepared about this, and if there will be changes which will make us to change our flow pattern or service provisions in general we are positive about it because we have observed the positive impacts so as the clinic we are ready for the changes which will come.

\section{Discussion}

In general, we found that the mHealth system was overall successfully implemented with high levels of acceptance and usability from both patients and providers; the system we designed functioned as intended. While fingerprint recognition encountered some feasibility limitations in the first months of testing, payments via mobile money were highly successful. Clinic management staff voiced excitement for the system's potential to bring the cash program to patients and simplify workflows; yet concerns about multiple systems, staffing shortages, and intermittent connectivity tempered enthusiasm, highlighting structural issues beyond the scope of the program.

Still, there were unintended benefits and consequences that we learned about along the way, many of which could impact scale-up efforts of clinic-based incentives for improving HIV care outcomes. Specifically, fingerprint identification plus automatic disbursement of mobile payments have strong potential as a means to efficiently implement clinic-based cash incentives in low-income country settings. In fact, utilization of mobile money has increased significantly in low-resource settings in particular (over $50 \%$ of Tanzanians have a mobile money account), and continues to grow quickly(30). As a result, social protection programs in low resource settings that utilize cash transfers are increasingly using mobile money instead of cash due to its multiple advantages, including the potential for increasing financial inclusion, decreased travel and time requirements for recipients, and increased accuracy and accountability(31,32). However, based on our results, the following should be considered: a) upfront effort needs to be expended to ensure that patient concerns about privacy are addressed, for example by allowing participants to opt-out of SMS notifications, or by providing assurance that SMS messages do not reveal anything about HIV status; b) while most participants had access to mobile phones and mobile money, providing access for all will be needed to successfully implement this system and consideration given to how to weigh this need against the ability to bring the intervention to scale;; c) implementation support in the clinic including universal training, incentive payments for staff to use the system, and ensuring there is a solid understanding of the benefits conferred to patients (e.g., decreasing loss to follow up) will be crucial; d) getting the fingerprint system right took more time and was more complicated than expected - issues relating to image quality, computing storage and creating the threshold precision level for fingerprint recognition resulted in a steep learning curve; e) unexpected benefits of the system included lending a sense of legitimacy and belonging for patients, a strong understanding among clinical staff of how such a system could help patients and simplify clinic operations, and as a result of the mobile money, the potential for increased savings and increased control over spending, as well as increasing intrahousehold bargaining power for women. These findings are supported by other research and data showing that mobile money payments (as compared to cash) 
provide an early entry point into the formal financial sector, and provide the opportunity for women to have more control over their money and how they spend it. (33-35)

It should be noted that some characteristics inherent to many clinical settings in resource constrained settings may limit the impact of any mHealth system. Many of these were mentioned by clinical staff in discussing the appropriateness of the mHealth system in this context; these include infrastructure (reliable WiFi networks, replacement tablets, secure storage), staffing shortages and turnover, and the need for universal training and sustained training support for using the system. These inherent limitations underscore the need for developing a system that easy to use, is easily scaled and does not rely on paper-based tracking systems and manual identification of eligible beneficiaries for a cash transfer program. In addition, working with a local technology firm who understands well the context and unique challenges that arise in these settings is essential, a type of partnership that benefitted this research.

This study has several limitations. For example, despite the implementation science focus of this work, gaining a true understanding of how this mHealth system might function outside of the study context can be challenging, particularly with significant levels of research staff involvement during the implementation phase. We attempted to gain an understanding of this dynamic by assessing the proportion of visits that were handled by the pharmacist versus the research staff at study end; these data showed a positive trend toward implementation as designed, with the pharmacist operating the system, allowing research staff to step away from the process. Additionally, we will have the opportunity to explore this aspect of implementation in more detail during phase 2 of our study(36). Phase 2, scheduled to begin in early 2021, is a cluster RCT in 32 clinics in Tanzania, and will provide ample opportunity to evaluate implementation outcomes in a setting that approaches "real world," where we can assess heterogeneity in implementation and its impact on the primary study outcome(36). Additionally, in-depth interviews conducted with a small subsample of study participants may not be representative of the full study population, and some data collection methods (e.g., structured observation in the clinics and the HITUES questions) were introduced toward the end of the study, so these data may not represent the full study experience of participants. Other limitations include the potential for social desirability bias to impact reported perceptions of the mHealth system among both participants and clinical staff, and the lack of data from PLHIV participants in the cash groups who received payments in cash rather than through mobile money.

\section{Conclusions}

We found that biometric identification and mobile payments were acceptable to most patients and staff in this semi-rural region of Tanzania. Biometric identification and mobile payments may provide a scalable mechanism to improve patient tracking and efficiently implement cash incentives in low-income country settings, and mobile money payments may result in the unintended benefit of increasing savings and providing a means to control spending. 


\section{Abbreviations}

PLHIV - People living with HIV/AIDS

ART - Antiretroviral therapy

RCT - Randomized controlled trial

IDI - In-depth interview

HITUES - Health Information Technology User Evaluation Scale

WHO - World Health Organization

\section{Declarations}

- Ethics approval and consent to participate: This study was approved by the University of California, Berkeley Office for Protection of Research Subjects and by the National Medical Research Institute of Tanzania. All study participants were required to provide written informed consent prior to study participation.

- Consent for publication: Not Applicable

- Availability of data and materials: The datasets used and analyzed during the current study are available from the corresponding author on reasonable request.

- Competing interests: The authors declare that they have no competing interests

- Funding: This study was funded by the National Institute of Mental Health (NIMH) grant number: R01MH112432-01A1

- Authors' contributions: LP analyzed the data and drafted the manuscript; CF assisted with data analysis and interpretation, data collection, and manuscript review and revisions; AM and AK conducted interviews, analyzed and interpreted qualitative data, and provided comments on the manuscript; SM designed the study, assisted with interpretation of data, and provided revisions and comments on the manuscript; PN oversaw all data collection efforts, contributed to the design of the study, and reviewed and provided comments on the manuscript.

- Acknowledgements: We are thankful to all of our study participants in Shinyanga, Tanzania, as well as the full HPON team, in particular Emmanuel Katabaro and Janeth Msasa. We are also grateful for the support of our collaborators at the Ministry of Health, Community Development, Gender, Elderly, and Children.

\section{References}

1. Avert. Global information and education on HIV and AIDS [Internet]. [cited 2019 Dec 1]. Available from: https://www.avert.org/professionals/hiv-around-world/sub-saharan-africa/overview 
2. HIV/AIDS JUNP on, others. Fast-track: ending the AIDS epidemic by 2030. Geneva: UNAIDS. 2014;

3. McCoy SI. Improving the Efficiency of HIV Testing With Peer Recruitment, Financial Incentives, and the Involvement of Persons Living with HIV Infection. Journal of. 2013;

4. Björkman-Nyqvist M. Evaluating the impact of short term financial incentives on HIV and STI incidence among youth in Lesotho: a randomized trial. In: 7th IAS Conference on HIV Pathogenesis, Treatment, and Prevention. Kuala Lumpur; 2013.

5. Baird SJ. Impact of a cash transfer program for schooling on prevalence of. In: HIV and HSV-2 in. Malawi: a;

6. de Walque D. Incentivising safe sex: a randomised trial of conditional cash transfers for HIV and sexually transmitted infection prevention in rural Tanzania. BMJ Open. 2012;2:000747.

7. Galarraga O. Conditional Economic Incentives to Improve HIV Treatment Adherence: Literature Review and Theoretical Considerations. AIDS and behavior. 2013;

8. Solomon S. The Impact of Voucher Incentives on Linkage to Care and ART Initiation among Drug Users. In: Chennai, India in 19th Conference on Retroviruses and Opportunistic Infections. 2012.

9. Haukoos JS. The effect of financial incentives on adherence with outpatient human immunodeficiency virus testing referrals from the emergency department. Acad Emerg Med. 2005;12(7):617-21.

10. Thornton R. The Demand for and Impact of Learning HIV Status: Evidence from a Field Experiment. American Economic Review. 2008(98):1829-63.

11. Cluver L. Child-focused state cash transfers and adolescent risk of HIV infection in South Africa: a propensity-score-matched case-control study. The Lancet Global Health. 2013;1(6):362-70.

12. Handa $S$. The government of Kenya's cash transfer program reduces the risk of sexual debut among young people age 15-25. PLoS One. Vol. 9. 2014. 85473 p.

13. Singer AW, Weiser SD, McCoy SI. Does Food Insecurity Undermine Adherence to Antiretroviral Therapy? A Systematic Review AIDS Behav. 2014;

14. Young S. A Review of the Role of Food Insecurity in Adherence to Care and Treatment Among Adult and Pediatric Populations Living with HIV and AIDS. AIDS and Behavior. 2013;

15. McCoy SI. Rationale and design of a randomized study of short-term food and cash assistance to improve adherence to antiretroviral therapy among food insecure HIV-infected adults in Tanzania. BMC Infect Dis. 2015;15:490.

16. Buzdugan R, Bautista-Arredondo S, McCoy and SI. The promise of behavioral economics for HIV/AIDS treatment and care. In: 21th International AIDS Conference. Durban: South Africa; 2016.

17. Chaiyachati $\mathrm{KH}$. Interventions to improve adherence to antiretroviral therapy: a rapid systematic review. AIDS. 2014;2:187-204.

18. El-Sadr WM. Effect of Financial Incentives on Linkage to Care and Viral Suppression. In: HPTN 065 in Conference on Retroviruses and Opportunistic Infections. 2015. 
19. Galarraga O, Sosa-Rubi SG. Conditional economic incentives to improve HIV prevention and treatment in low-income and middle-income countries. Lancet HIV. 2019 Oct;6(10):e705-14.

20. Fahey CA, Njau PF, Katabaro E, Mfaume RS, Ulenga N, Mwenda N, et al. Financial incentives to promote retention in care and viral suppression in adults with HIV initiating antiretroviral therapy in Tanzania: a three-arm randomised controlled trial. The Lancet HIV [Internet]. 2020 Sep 3 [cited 2020 Oct 7]; Available from: http://www.sciencedirect.com/science/article/pii/S2352301820302307

21. Fahey CA, Mwenda N, Bhattarai PR, Mneney J, Katabaro E, Njau PF, et al. Feasibility and acceptability of a biometric mHealth system for monitoring retention in HIV services and delivering financial incentives to adults initiating antiretroviral therapy in Tanzania. In 2019.

22. Proctor EK, Landsverk J, Aarons G, Chambers D, Glisson C, Mittman B. Implementation research in mental health services: an emerging science with conceptual, methodological, and training challenges. Administration and Policy in Mental Health and Mental Health Services Research. 2009;36(1):24-34.

23. Ministry of Health and Social Welfare. Tanzania National eHealth Strategy 2012 - 2018. Tanzania: Ministry of Health, Community Development, Gender, Elderly and Children, National AIDS Control Programme; 2013.

24. Bank W. Tanzania mainland poverty assessment. World Bank; 2019.

25. Tanzania Commission for, Zanzibar AIDS Commission AC. Tanzania HIV Impact Survey (THIS) 20162017: Final Report. Dar es Salaam, Tanzania; 2018 Dec.

26. Schnall R, Cho H, Liu J. Health Information Technology Usability Evaluation Scale (Health-ITUES) for Usability Assessment of Mobile Health Technology: Validation Study. JMIR Mhealth Uhealth. 2018 Jan 5;6(1):e4.

27. StataCorp. Stata Statistical Software: Release 15. College Station, TX: StataCorp LLC; 2017.

28. Tolley EE, Ulin PR, Mack N, Robinson ET, Succop SM. Qualitative Methods in Public Health: A Field Guide for Applied Research. John Wiley \& Sons; 2016. 531 p.

29. Dedoose Version 8.0.35, web application for managing, analyzing, and presenting qualitative and mixed method research data [Internet]. Los Angeles, CA: SocioCultural Research Consultants, LLC; 2018. Available from: www.dedoose.com

30. Ansar S, Singer D, Klapper L, Demirguc-Kunt A. The Global Findex Database 2017: Measuring Financial Inclusion and the Fintech Revolution. World Bank Group; 2018.

31. Ford E. The potential of digital cash transfers to strengthen the link between humanitarian assistance and social protection. Bath Papers in International Development and Wellbeing; 2017.

32. Chehade N, McConaghy P, Meier CM. HUMANITARIAN CASH TRANSFERS AND FINANCIAL INCLUSION. 2020;

33. Aker JC, Boumnijel R, McClelland A, Tierney N. Payment Mechanisms and Antipoverty Programs: Evidence from a Mobile Money Cash Transfer Experiment in Niger. Economic Development and Cultural Change. 2016 Aug 15;65(1):1-37. 
34. Ahmad AH, Green C, Jiang F. Mobile Money, Financial Inclusion and Development: A Review with Reference to African Experience. Journal of Economic Surveys. 2020;34(4):753-92.

35. UN Capital Development Fund. Better Than Cash Alliance [Internet]. Better Than Cash Alliance. [cited 2021 Mar 12]. Available from: https://www.betterthancash.org/

36. Packel L, Njau P, Fahey C, Ramadhani A, Dow WH, Jewell NP, et al. Optimizing the efficiency and implementation of cash transfers to improve adherence to antiretroviral therapy: study protocol for a cluster randomized controlled trial. Trials. 2020 Nov 23;21(1):963.

\section{Tables}


Table 1.

Afya mHealth Components and lessons learned

\begin{tabular}{|c|c|c|c|}
\hline Component & Functionality & Intention & Lessons Learned \\
\hline \multirow[t]{4}{*}{$\begin{array}{l}\text { Pharmacy- } \\
\text { based } \\
\text { monitoring } \\
\text { patient visit } \\
\text { attendance }\end{array}$} & $\begin{array}{l}\text { Automatically logs patient } \\
\text { attendance and allows entry } \\
\text { of next visit date; }\end{array}$ & $\begin{array}{l}\text { Track patient } \\
\text { medication pickup in } \\
\text { nearly real-time (robust } \\
\text { measure of adherence) }\end{array}$ & $\begin{array}{l}\text { The program needs to } \\
\text { have readily available } \\
\text { benefits for users that } \\
\text { are clear to clinic staff }\end{array}$ \\
\hline & $\begin{array}{l}\text { with biometric ID and inputs } \\
\text { medication pickup, next } \\
\text { appointment into the system }\end{array}$ & $\begin{array}{l}\text { Pharmacists entering } \\
\text { data into the mHealth } \\
\text { system to document } \\
\text { receipt and type of } \\
\text { medication given }\end{array}$ & $\begin{array}{l}\text { Training and } \\
\text { engagement with clinic } \\
\text { staff as partners will be } \\
\text { essential as their buy-in } \\
\text { is key to successful } \\
\text { implementation }\end{array}$ \\
\hline & \multirow[t]{2}{*}{$\begin{array}{l}\text { Robust measure of } \\
\text { adherence - last stop of clinic } \\
\text { visit, made sense for cash to } \\
\text { be disbursed here }\end{array}$} & $\begin{array}{l}\text { Overcomes key } \\
\text { information gaps that } \\
\text { could benefit care: }\end{array}$ & \\
\hline & & $\begin{array}{l}\text { Obtain next visit date } \\
\text { for accurate } \\
\text { measurement of } \\
\text { retention in care }\end{array}$ & \\
\hline \multirow[t]{4}{*}{ Biometric ID } & \multirow{4}{*}{$\begin{array}{l}\text { Identifies patient using } \\
\text { fingerprint, logs appointment } \\
\text { attendance for cash } \\
\text { eligibility, provides near real- } \\
\text { time information about visit } \\
\text { attendance }\end{array}$} & $\begin{array}{l}\text { Saves clinic time by } \\
\text { efficiently and } \\
\text { rigorously monitoring } \\
\text { patient visit attendance }\end{array}$ & \multirow{3}{*}{$\begin{array}{l}\text { Overall, fingerprint } \\
\text { identification was } \\
\text { highly acceptable to } \\
\text { patients and clinicians } \\
\text { and may increase the } \\
\text { system's perceived } \\
\text { legitimacy. } \\
\text { iterative improvements } \\
\text { were required to } \\
\text { overcome fingerprint } \\
\text { recognition challenges }\end{array}$} \\
\hline & & \multirow{3}{*}{$\begin{array}{l}\text { Avoids participant } \\
\text { misclassification that } \\
\text { can arise from lengthy } \\
\text { clinic IDs that must be } \\
\text { transcribed from paper } \\
\text { records to the database }\end{array}$} & \\
\hline & & & \\
\hline & & & $\begin{array}{l}\text { It took a while to get } \\
\text { this right. }\end{array}$ \\
\hline \multirow{3}{*}{$\begin{array}{l}\text { Financial } \\
\text { incentive } \\
\text { disbursement } \\
\text { integrated } \\
\text { with mobile } \\
\text { money }\end{array}$} & \multirow{3}{*}{$\begin{array}{l}\text { Automatically sends cash for } \\
\text { visit attendance via the } \\
\text { mobile money provider used } \\
\text { by the client, seamlessly } \\
\text { incorporates any program } \\
\text { "rules" without human error }\end{array}$} & $\begin{array}{l}\text { Simplifies the logistics } \\
\text { of disbursing cash } \\
\text { payments }\end{array}$ & $\begin{array}{l}\text { Overall, the mobile } \\
\text { money disbursement } \\
\text { was highly acceptable }\end{array}$ \\
\hline & & $\begin{array}{l}\text { Increases privacy } \\
\text { compared to cash }\end{array}$ & $\begin{array}{l}\text { Some concerns about } \\
\text { privacy and autonomy } \\
\text { in spending }\end{array}$ \\
\hline & & $\begin{array}{l}\text { Auto transfer connected } \\
\text { to fingerprint scan } \\
\text { bolsters connection } \\
\text { between visit } \\
\text { attendance and cash }\end{array}$ & $\begin{array}{l}\text { At scale, automated } \\
\text { cash distribution will be } \\
\text { essential for feasible } \\
\text { implementation of } \\
\text { financial incentives in } \\
\text { HIV clinics. }\end{array}$ \\
\hline
\end{tabular}


Table 2.

Implementation Science outcomes table, with population of interest indicated in []

\begin{tabular}{|c|c|c|c|}
\hline $\begin{array}{l}\text { Proctor } \\
\text { outcome }\end{array}$ & Adapted Definition & $\begin{array}{l}\text { Measure/Indicator } \\
\text { [population perspective] }\end{array}$ & Data Source \\
\hline Acceptability & $\begin{array}{l}\text { The degree to which the mHealth } \\
\text { components are considered } \\
\text { reasonable and satisfactory } \\
\text { given current context }\end{array}$ & $\begin{array}{l}\text { \% consented to mobile } \\
\text { money [PLHIV] } \\
\text { \% consented to biometric } \\
\text { ID [PLHIV] } \\
\text { Preference for mobile } \\
\text { money vs. cash [PLHIV] } \\
\text { Preference for traditional } \\
\text { paper-based system vs. } \\
\text { biometric ID [PLHIV \& } \\
\text { Clinical Staff] } \\
\text { Clinical staff } \\
\text { perspectives on the } \\
\text { mHealth system [Clinical } \\
\text { Staff] }\end{array}$ & $\begin{array}{l}\text { Baseline/endline } \\
\text { survey with } \\
\text { PLHIV } \\
\text { In-depth } \\
\text { interviews }\end{array}$ \\
\hline Appropriateness & $\begin{array}{l}\text { The perceived fit of the mHealth } \\
\text { system components within the } \\
\text { existing context }\end{array}$ & $\begin{array}{l}\text { HITUES [PLHIV] } \\
\text { Clinical staff } \\
\text { perspectives on mHealth } \\
\text { system [Clinical Staff] }\end{array}$ & $\begin{array}{l}\text { HITUES } \\
\text { In-depth } \\
\text { interviews with } \\
\text { Clinical Staff }\end{array}$ \\
\hline Adoption & $\begin{array}{l}\text { The level of uptake of the } \\
\text { mHealth system components }\end{array}$ & $\begin{array}{l}\text { \% with mobile money } \\
\text { linked to mHealth at } \\
\text { endline [PLHIV] } \\
\text { \% visits where the } \\
\text { pharmacist was } \\
\text { operating the mHealth } \\
\text { system } \\
\text { [Clinical Staff] }\end{array}$ & $\begin{array}{l}\text { mHealth system } \\
\text { data } \\
\text { Structured } \\
\text { observations }\end{array}$ \\
\hline Fidelity & $\begin{array}{l}\text { The degree to which the } \\
\text { components of the mHealth } \\
\text { system were implemented as } \\
\text { intended }\end{array}$ & $\begin{array}{l}\text { \# visits mHealth system } \\
\text { not used [Clinical Staff] } \\
\text { \% eligible receiving cash } \\
\text { transfers [PLHIV] } \\
\text { \% cash transfers sent } \\
\text { through mobile money } \\
\text { [PLHIV] } \\
\text { \% mobile transfers } \\
\text { requiring manual } \\
\text { resending [PLHIV] }\end{array}$ & $\begin{array}{l}\text { Structured } \\
\text { observations } \\
\text { mHealth system } \\
\text { data }\end{array}$ \\
\hline Feasibility & $\begin{array}{l}\text { The degree to which the } \\
\text { technical aspects of the mHealth }\end{array}$ & $\begin{array}{l}\% \text { with access to mobile } \\
\text { money [PLHIV] }\end{array}$ & $\begin{array}{l}\text { Baseline/endline } \\
\text { survey }\end{array}$ \\
\hline
\end{tabular}


system functioned as intended (technology gaps or glitches)
$\%$ with mobile phones [PLHIV]

$\%$ of scans that were successful [Clinical Staff]

Average number of scans required [Clinical Staff]

Number/proportion of errors in mobile transfers [Clinical Staff]
The degree to which the mHealth system might be scalable and sustainable in HIV clinics
Barriers to scale-up [Clinical Staff]
In-depth interviews

mHealth data system
In-depth interviews 
Table 3.

PLHIV participant demographics at study enrollment for the full study, those included in the IDIs, and those who were surveyed with HITUES.

\begin{tabular}{|c|c|c|c|}
\hline & Total & Included in IDIs & Included in HITUES \\
\hline & $N=530$ & $\mathrm{~N}=25$ & $N=104$ \\
\hline Age (years) at baseline & $36.1(10.2)$ & $33.8(10.3)$ & $35.9(10.7)$ \\
\hline \multicolumn{4}{|l|}{ Sex } \\
\hline Male & $200(37.7 \%)$ & $10(40.0 \%)$ & $39(37.5 \%)$ \\
\hline Female & $330(62.3 \%)$ & $15(60.0 \%)$ & $65(62.5 \%)$ \\
\hline \multicolumn{4}{|l|}{ Ever attended school } \\
\hline No & $113(21.3 \%)$ & $3(12.0 \%)$ & $20(19.2 \%)$ \\
\hline Yes & $417(78.7 \%)$ & $22(88.0 \%)$ & 84 (80.8\%) \\
\hline \multicolumn{4}{|l|}{ Current marital status (baseline) } \\
\hline Single/never married/no partner & $39(7.4 \%)$ & $0(0.0 \%)$ & $5(4.8 \%)$ \\
\hline Unmarried, with partner & $57(10.8 \%)$ & $3(12.0 \%)$ & $16(15.4 \%)$ \\
\hline Married (monogamous) & $200(37.7 \%)$ & $10(40.0 \%)$ & $34(32.7 \%)$ \\
\hline Married (polygamous) & $31(5.8 \%)$ & $0(0.0 \%)$ & $7(6.7 \%)$ \\
\hline Widowed & $45(8.5 \%)$ & $1(4.0 \%)$ & $9(8.7 \%)$ \\
\hline Divorced & $44(8.3 \%)$ & $2(8.0 \%)$ & $7(6.7 \%)$ \\
\hline Separated & $114(21.5 \%)$ & $9(36.0 \%)$ & $26(25.0 \%)$ \\
\hline \multicolumn{4}{|l|}{ WHO Clinical Stage (baseline) } \\
\hline Stage 1 & $281(53.0 \%)$ & $19(76.0 \%)$ & $58(55.8 \%)$ \\
\hline Stage 2 & 187 (35.3\%) & $6(24.0 \%)$ & 31 (29.8\%) \\
\hline Stage 3 & 59 (11.1\%) & $0(0.0 \%)$ & $13(12.5 \%)$ \\
\hline Stage 4 & $3(0.6 \%)$ & 0 (0.0\%) & $2(1.9 \%)$ \\
\hline
\end{tabular}


Table 4.

Mean Scores of PLHIV on the Health Information Technology User Evaluation Scale applied to fingerprint identification and mobile money

\begin{tabular}{|lllll|}
\hline HITUES Domain & Mean & Std Error & Lower95 & Upper95 \\
\hline Fingerprint ID ( $\mathbf{n = 1 0 4 )}$ & & & & \\
\hline Impact & 4.10 & 0.07 & 3.96 & 4.24 \\
\hline Usefulness & 4.01 & 0.07 & 3.87 & 4.15 \\
\hline Ease of Use & 4.16 & 0.07 & 4.03 & 4.30 \\
\hline User Control & 4.21 & 0.07 & 4.07 & 4.34 \\
\hline Fingerprint Overall Average & 4.10 & $\mathbf{0 . 0 6}$ & $\mathbf{3 . 9 8}$ & 4.21 \\
\hline Mobile Money (n=53) & & & & \\
\hline Impact & 4.32 & 0.11 & 4.10 & 4.54 \\
\hline Usefulness & 4.18 & 0.08 & 4.02 & 4.34 \\
\hline Ease of Use & 4.32 & 0.09 & 4.15 & 4.49 \\
\hline User Control & 3.80 & 0.06 & 3.67 & 3.93 \\
\hline Mobile Money Overall Average & $\mathbf{4 . 2 0}$ & $\mathbf{0 . 0 8}$ & $\mathbf{4 . 0 4}$ & 4.36 \\
\hline
\end{tabular}

Figures 


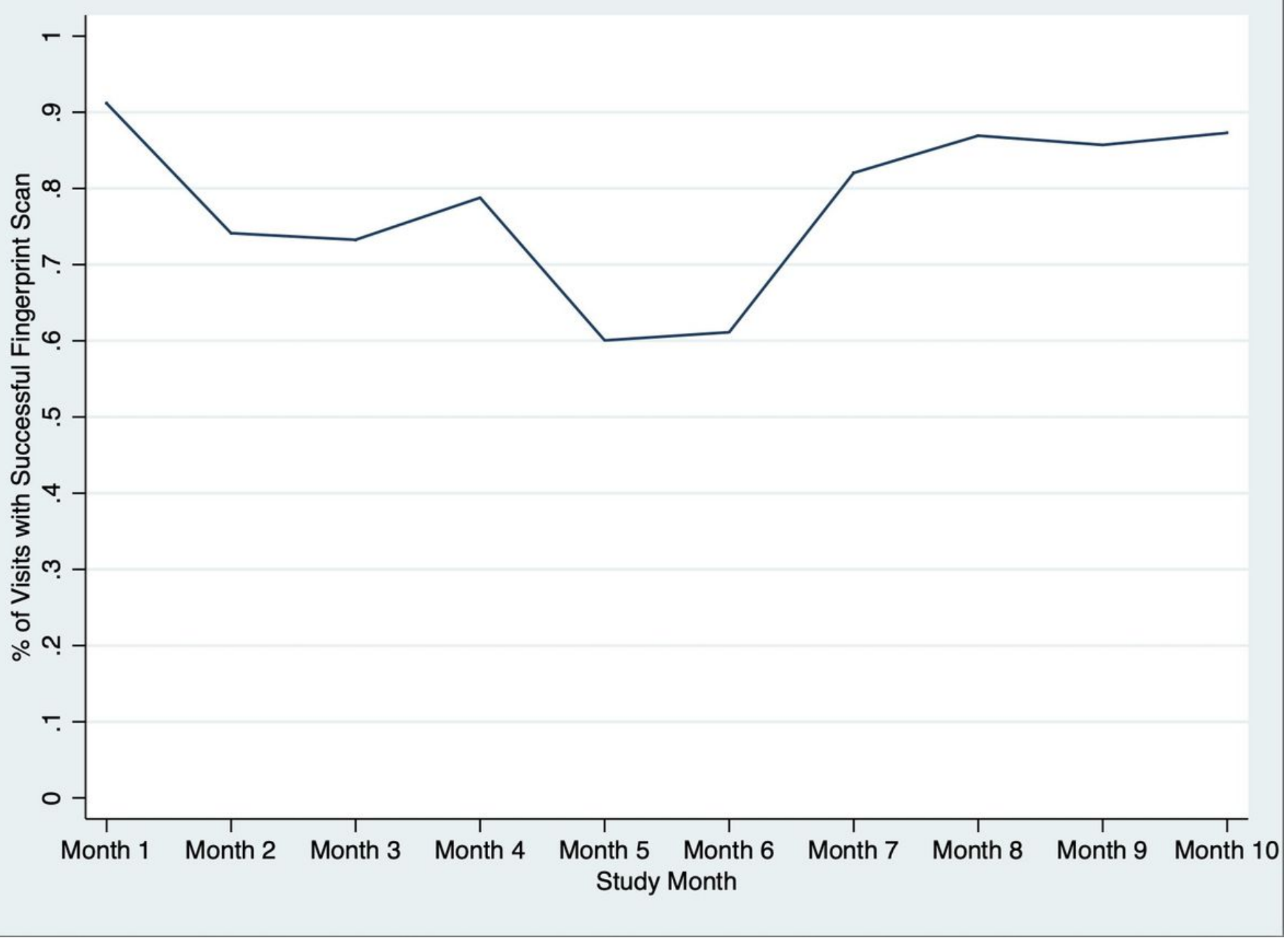

Figure 1

Fingerprint scan success rate, by study month

\section{Supplementary Files}

This is a list of supplementary files associated with this preprint. Click to download.

- SupplementalMaterial.docx

- StaRIchecklistforauthorcompletion.docx 